\title{
17 $\beta$-estradiol-containing liposomes as a novel delivery system for the antisense therapy of ER-positive breast cancer: An in vitro study on the MCF-7 cell line
}

\author{
ZBYNEK HEGER $^{1,2}$, JAROMIR GUMULEC $^{3,4}$, NATALIA CERNEI ${ }^{1,3}$, KATERINA TMEJOVA $^{1,3}$, \\ PAVEL KOPEL $^{1,3}$, JAN BALVAN ${ }^{3,4}$, MICHAL MASARIK ${ }^{1,3,4}$, ONDREJ ZITKA ${ }^{1-3}$, \\ MIROSLAVA BEKLOVA $^{2,3}$, VOJTECH ADAM ${ }^{1,3}$ and RENE KIZEK ${ }^{1,3}$ \\ ${ }^{1}$ Department of Chemistry and Biochemistry, Mendel University in Brno, CZ-613 00 Brno; \\ ${ }^{2}$ Department of Ecology and Diseases of Game, Fish and Bees, Faculty of Veterinary Hygiene and Ecology, \\ University of Veterinary and Pharmaceutical Sciences, CZ-612 42 Brno; ${ }^{3}$ Central European Institute of Technology, \\ Brno University of Technology, CZ-616 00 Brno; ${ }^{4}$ Department of Pathological Physiology, \\ Faculty of Medicine, Masaryk University, CZ-612 00 Brno, Czech Republic
}

Received May 21, 2014; Accepted July 11, 2014

DOI: $10.3892 / o r .2014 .3627$

\begin{abstract}
The present study suggests and describes the application of a delivery system for antisense oligonucleotides against mRNA encoding estrogen receptor proteins $\alpha$ and $\beta$. The delivery system is composed of a cationic liposome envelope containing $17 \beta$-estradiol $\left(\mathrm{E}_{2}\right)$ in its structure. Cationic liposomes protect cargo against the extracellular matrix, and $\mathrm{E}_{2}$ can increase its shuttling efficiency into cells. Using MCF-7 cells derived from estrogen receptor-positive ductal carcinoma, treatment with liposomes against $\mathrm{ER} \alpha$ was found to decrease MCF-7 proliferation, and importantly the application of both the antisense against ER $\alpha$ and $\beta$ exhibited an antiproliferative effect expressed as cell viability. Using qRT-PCR, it was shown that $M T 1 A, N F-\kappa B 1$ and $K$-ras genes, but not $T F F 1$, were downregulated using $\mathrm{E}_{2}$-based liposomes (evaluated at $\mathrm{P}=0.05$ ). Further indicators of oxidative stress were employed to assess the effect on treatment efficiency. Glutathione (GSH/ GSSG redox ratio), metallothionein (MT) and malondialdehyde (MDA) confirmed a positive effect of antisense therapy resulting in their decreased levels in the MCF-7 cells. Based on these data, we suggest that $\mathrm{E}_{2}$-based liposomes offer sufficient transfer efficiency and moreover, due to the effect on $N F-\kappa B 1$, MT and GSH, tumor cells can be chemosensitized to increase treatment effectiveness.
\end{abstract}

Correspondence to: Professor Rene Kizek, Department of Chemistry and Biochemistry, Mendel University in Brno, Zemedelska 1, CZ-613 00 Brno, Czech Republic

E-mail:kizek@sci.muni.cz

Key words: antisense therapy, delivery, glutathione, liposome, malondialdehyde, metallothionein

\section{Introduction}

The use of antisense oligonucleotides (ASOs) to control functions in diseased cells was first recognized more than 20 years ago (1). ASOs, downregulating the expression of target molecules via mRNA silencing, exhibit tissue specificity and can be used to ameliorate the symptoms of various clinical conditions and to significantly improve the quality of life of patients (2-4). In the fight against malignant neoplasms, the strategy employing antisense therapy can block cancer genes, which produce malicious proteins; hence, ASOs have the potential to become a powerful weapon in this field (5). Moreover, it has been demonstrated that the use of a single treatment strategy against cancer is generally ineffective due to the multifactorial nature of this disease (6). Therefore, increased attention is being given to the combination of antisense therapy and chemotherapy $(6,7)$.

Although the promising properties of ASOs have been recognized, the lack of methods applicable for ASO delivery avoiding the degradation of ASOs through the delivery routes is the major challenge in the wide utilization of these oligonucleotides in clinical practice. Thereby, the development of this new class of drugs has been delayed because of the difficulties in DNA, or RNA delivery, to cells (8), where ubiquitous nucleases may attack a cargo (9). Moreover, the transfer across membranes is also complicated due to the hydrophilic character and anionic backbone contained in the ASO structure (10).

Therefore, an effective delivery system is essential to protect a cargo against premature degradation. Regarding this issue, cationic liposomes have been demonstrated as a promising tool with which to protect ASOs from the extracellular matrix with potential to transport these molecules into cells (11-13). Liposomes can be safely administered to humans, because of their low toxicity and immunogenicity (14). However, this method still has the disadvantage of low efficacy of cargo 
transfer and therefore, improvement of transfer is crucial for their further utilization (15).

This study focused on the construction of cationic liposomes containing $\mathrm{E}_{2}$ in the lipid bilayer and antisense oligonucleotides designed against the human transcription factors estrogen receptor $\alpha(\mathrm{ER} \alpha)$ and $\beta(\mathrm{ER} \beta)$ enclosed in their inner cavities. The $\mathrm{E}_{2}$ was employed to replace cholesterol, constituting a lipid bilayer of liposomes, to increase the efficiency of transporters. To study the effects of liposome-based transporters on proliferation, gene expression and redox status, a subclone of the well-characterized human estrogen receptorpositive breast cancer cell line MCF-7 was employed, as one of the $\mathrm{E}_{2}$-liposome transporters specifically inhibits $\mathrm{MCF}-7$ cell proliferation and affects gene expression. Moreover, the levels of oxidative indicators were determined.

\section{Materials and methods}

Chemicals and $\mathrm{pH}$ measurement. The working solutions such as buffers or the standard solution of 17ß-estradiol $\left(\mathrm{E}_{2}\right)$ were prepared daily by diluting the stock solutions. Estradiol, oligonucleotides and other agents were purchased from SigmaAldrich (St. Louis, MO, USA) at ACS purity, unless noted otherwise. The antisense oligonucleotides against estrogen receptor $\alpha$ and $\beta$ (Sigma-Aldrich) were designed and the sequences are shown in Table I.

Preparation of liposomes. Liposomes were prepared following the lipidic thin-film hydration method. Briefly, $100 \mathrm{mg}$ of cholesterol, $100 \mathrm{mg}$ of 1,2-dioleoyl-sn-glycero-3-phosphorac-(1-glycerol) sodium salt and $100 \mathrm{mg}$ of phosphatidylcholine were dissolved in chloroform $(4.5 \mathrm{ml})$. A lipid film was obtained by rotary evaporation of solvent and the residual chloroform was blown out by nitrogen to remove the organic solvent until a thin film was formed. For encapsulation into liposomes, $2 \mathrm{ml}$ of solution containing $17 \beta$-estradiol and ASOs was used. The samples were homogenized in ultrasonic bath Sonorex Digital 10P (Bandelin, Berlin, Germany) for $15 \mathrm{~min}$. The homogenized mixtures were then heated and shaken for $15 \mathrm{~min}$ at $60^{\circ} \mathrm{C}$ using the Thermomixer comfort (Eppendorf AG, Hamburg, Germany). The samples were then washed several times with Britton-Robinson buffer $(\mathrm{pH}, 10.0)$ using Amicon 3K (Millipore, Billerica, MA, USA).

Determination of $17 \beta$-estradiol content in the liposomes. The hormone content in the liposomes was determined using AIA-Pack E2 sta assay (Tosoh Corp., Tokyo, Japan) according to the manufacturer's instructions, using immunoanalyzer AIA 600 II (Tosoh).

Determination of total RNA content in the liposomes. The total amount of RNA in the liposomes was determined using an electrochemical analyzer 663 VA Stand (Metrohm, Herissau, Switzerland) using square wave voltammetry with a three-electrode system, according to our previous study (16). For each electrochemical analysis, $10 \mu \mathrm{l}$ of antisense RNA solution was used.

MCF-7 cell culture. MCF-7 epithelial breast cancer cells were maintained in Dulbecco's modified Eagle's medium (DMEM;
Table I. Antisense oligonucleotide sequences.

Antisense $1 \alpha$ 5'-GACCATGACCATGACCCT-3'

Antisense $1 \beta$ 5'-TGTGCCTGGCTAGAGATC-3'

Gibco-BRL, Grand Island, NY, USA), supplemented with $10 \%$ (v/v) fetal bovine serum (Sigma-Aldrich), $1 \mathrm{mM}$ sodium pyruvate, non-essential amino acids and $100 \mu \mathrm{g} / \mathrm{ml}$ penicillin and streptomycin (Sigma-Aldrich). Liposomes, containing antisense oligonucleotides at different concentrations, were applied directly into the medium to treat the cells and were labeled as L2, L3 and L4 and contained $1 \mu \mathrm{M}$ and/or $10 \mu \mathrm{M}$ of single or both types of oligonucleotides. L1 did not contain any ASOs and served as a control. The treatment of MCF-7 cells was conducted for $12 \mathrm{~h}$.

Cell proliferation assessment using real-time cell-based assay (RTCA). Real-time cell-based assay xCELLigence (Roche Applied Science and ACEA Biosciences, San Diego, CA, USA) consisted of four main components: RTCA analyser, RTCA station, RTCA computer with integrated software and disposable E-plate 16. First, the optimal seeding concentration for the proliferation and cytotoxic assays was determined. After seeding, the total number of cells (in $200 \mu \mathrm{l}$ medium of each well in the E-plate 16, the attachment, proliferation and spreading of the cells) was monitored every $15 \mathrm{~min}$. All the experiments were carried out for $65 \mathrm{~h}$. The results are expressed as cell viability using the software of the manufacturers (Roche Applied Science and ACEA Biosciences).

Microscopy. Eclipse TS100 inverted phase contrast microscope (Nikon Instruments, Amsterdam, The Netherlands) with a x20 magnification lens was used to view the cell cultures in cultivation flasks. The images were obtained directly using the C-5060 camera (Olympus, Tokyo, Japan).

RNA isolation and reverse transcription. High pure total-RNA isolation kit (Roche, Basel, Switzerland) was used to isolate RNA from the treated cells. The medium was removed and the samples were washed twice with $5 \mathrm{ml}$ of ice-cold PBS. The cells were scraped off, transferred to clean tubes and centrifuged at 20,800 x g for $5 \mathrm{~min}$ at $4^{\circ} \mathrm{C}$ (Microcentrifuge 5417R; Eppendorf AG, Hamburg, Germany). After this step, lysis buffer was added and RNA isolation was carried out according to the manufacturer's instructions. The isolated RNA was used for cDNA synthesis. The transcription of RNA (600 ng) was carried out using Transcriptor First Strand cDNA synthesis kit (Roche, Basel, Switzerland) according to the manufacturer's instructions. Prepared cDNA $(20 \mu 1)$ from total-RNA was diluted with RNase-free water to $100 \mu \mathrm{l}$ and subsequently $5 \mu \mathrm{l}$ was directly analyzed using the LightCycler 480 real-time PCR system (Roche Applied Science).

Quantitative polymerase chain reaction $(q-P C R)$. q-PCR was performed in triplicate using the TaqMan gene expression assay system with the LightCycler 480 real-time PCR system, 
and the amplified DNA was analyzed by the comparative $\mathrm{Ct}$ method using $\beta$-actin as an endogenous control for metallothionein $M T 1 A, K$-ras, TFFl and $N F-\kappa B l$ gene expression quantification. The primer and probe sets for $\beta$-actin (assay ID: Hs99999903_m1), MT1A (Hs00831826_s1), K-ras (Hs00364284_g1), NF- $\kappa B 1$ (Hs00765730_m1) and TTF1 (Hs00907239_m1) were selected from TaqMan gene expression assays (Life Technologies, Grand Island, NY, USA). The thermal profile for q-PCR was as follows: initial incubation at $50^{\circ} \mathrm{C}$ for $2 \mathrm{~min}$ followed by denaturation at $95^{\circ} \mathrm{C}$ for $10 \mathrm{~min}$ and then 45 cycles at $95^{\circ} \mathrm{C}$ for $15 \mathrm{sec}$ and $60^{\circ} \mathrm{C}$ for $1 \mathrm{~min}$. The total volume of the reaction mixture was $20 \mu 1$.

Preparation of MCF-7 cells for analyses. The harvested MCF-7 cells were frozen by liquid nitrogen to disrupt their structure. The frozen sample was further homogenized using ultrasonic homogenizer SONOPLUS mini20 (Bandelin electronic, Berlin, Germany). Subsequently, $1 \mathrm{ml}$ of $0.2 \mathrm{M}$ phosphate buffer ( $\mathrm{pH}, 7.0)$ was added and the sample was homogenized for $5 \mathrm{~min}$. The homogenate was further centrifuged using Microcentrifuge 5417R under the following conditions at $4^{\circ} \mathrm{C}$ for $15 \mathrm{~min}$. Finally, the supernatant was filtered through a membrane filter $(0.45-\mu \mathrm{m}$ nylon filter disk; Millipore, Billerica, MA, USA) and analyzed.

Determination of the total protein content. The total protein content was determined for results standardization and was performed using SKALAB CBT 600T kit (Skalab, Svitavy, Czech Republic) according to the manufacturer's instructions. For analysis, the BS-400 automated spectrophotometer (Mindray, Schenzhen, China) was used.

Determination of the metallothionein content with differential pulse voltammetry $(D P V)$. Differential pulse voltammetric (DPV) measurements were performed with the 747 VA Stand instrument connected to the 693 VA Processor and 695 Autosampler (Metrohm, Herissau, Switzerland), using a standard cell with three electrodes, according to our previous study (17).

High performance liquid chromatography coupled with electrochemical detector for determination of glutathiones. Contents of reduced and oxidized glutathiones (GSH and GSSG, respectively) were determined in the MCF-7 cell culture after liposome treatment using high performance liquid chromatography coupled with an electrochemical detector (HPLC-ED) system under the conditions used in our previous study (18).

Spectrophotometric determination of malondialdehyde (MDA). Three hundred milliliters of the sample was mixed with $10 \mu \mathrm{l}$ of $0.5 \mathrm{M}$ butylated hydroxytoluene in $96 \%$ ethanol $(\mathrm{v} / \mathrm{v})$ and $310 \mu \mathrm{l}$ of $20 \%$ trichloroacetic acid (v/v) prepared in $0.6 \mathrm{M} \mathrm{HCl}$. After $20 \mathrm{~min}$ of incubation on ice, the mixture was centrifuged at $11,000 \mathrm{rpm}$ for $15 \mathrm{~min}$ (Microcentrifuge 5417R). Subsequently, $400 \mu 1$ of the supernatant was mixed with $800 \mu \mathrm{l}$ of $30 \mathrm{mM}$ thiobarbituric acid and the mixture was incubated at $90^{\circ} \mathrm{C}$ for $30 \mathrm{~min}$. After cooling to room temperature, the absorbance of MDA was measured using the BS-400 spectrophotometer at a wavelength of $535 \mathrm{~nm}$.
Descriptive statistics. Mathematical analysis of the data and their graphical interpretation were carried out using Microsoft Excel $^{\circledR}$, Word ${ }^{\circledR}$ and PowerPoint ${ }^{\circledR}$ (Microsoft, Redmond, WA, USA). The results are expressed as mean \pm standard deviation (SD) unless noted otherwise. Statistical significance of the differences in gene expression was evaluated at $\mathrm{P}=0.05$.

\section{Results and Discussion}

The main challenge facing the approach using the delivery of antisense oligonucleotides (ASO) to target tumor cells is how to keep them intact to ubiquitous nucleases. Moreover, the hydrophilic character and anionic backbone of antisense oligonucleotides reduce the probability of their transfer across membranes (10). Thereby, liposomes were employed to protect ASOs in our study. Zhong et al reported that, due to their properties, liposomes continue to evolve as a promising tool for the delivery of potentially useful therapeutic agents (11). Therefore, we suggested estradiol-based liposomes operating on the principle of natural affinity of hormone and estrogen receptor proteins. Cholesterol (precursor of $17 \beta$-estradiol or $E_{2}$ ), which is commonly applied as the hydrophilic part of the lipid bilayers of liposomes (19), was replaced by $\mathrm{E}_{2}$. This complex offers similar hydrophilic properties and moreover the possibility to target the liposomes towards transcription factors $(E R \alpha$ and $E R \beta)$. Furthermore, it was shown that $E_{2}$ enhances ASO uptake and therefore, the transfection efficiency due to the interaction with fundamental components of the plasma membrane, which causes the alteration in its physical properties (20).

The scheme of $E_{2}$-based liposome interaction with cells is shown in Fig. 1. First, endocytosis occurs, since liposomes have been shown to be preferentially internalized through endocytosis (21). Acidification of endosomes causes release of ASOs into the cytoplasm and the formation of duplexes with mRNA encoding target protein due to Watson-Crick hybridization thus leading to mRNA degradation and/or inhibition of translation (10).

$17 \beta$-estradiol-based liposomes loaded with ASOs. Following the lipidic thin-film hydration method (22), we synthesized four different types of $17 \beta$-estradiol-based liposomes loaded with ASOs offering a powerful approach with which to selectively target and inhibit gene expression, critical in disease progression. As shown in Fig. 2A, liposomes L1 were prepared with no ASO cargo and were considered as the control. Other types of liposomes were prepared in the same manner, containing $\mathrm{E}_{2}$ in their lipidic envelopes, but moreover they were loaded with antisense ER $\alpha$ (Fig. 2B) named liposome L2, antisense ER $\beta$ (Fig. 2C) named liposome L3 and with both types of antisense sequences (Fig. 2D) named liposome L4. The antisense sequences used in our study are complementary to mRNAs encoding human transcription factors (ER $\alpha$ and/or $\beta)$ and thus they are able to target and modulate the receptor's responses.

To obtain the basic characteristics of liposome transporters, the hormone content was evaluated using immunochemistry and total RNA content using electrochemistry. It clearly follows from the results obtained that there was no distinct variation in $17 \beta$-estradiol content among the four types of liposomes ranging between 7-7.2 $\mathrm{pg} / \mathrm{ml}$ with an average of 


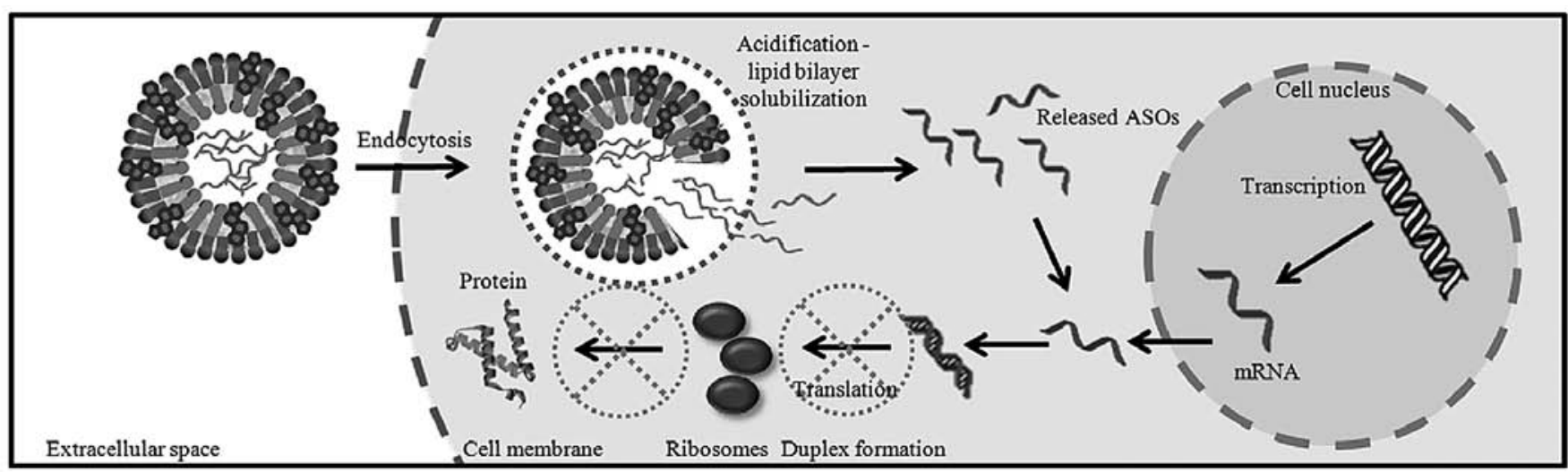

Figure 1. Scheme showing the antisense effect of antisense oligonucleotides encapsulated in liposomes on estrogen receptor protein formation. ASOs, antisense oligonucleotides.

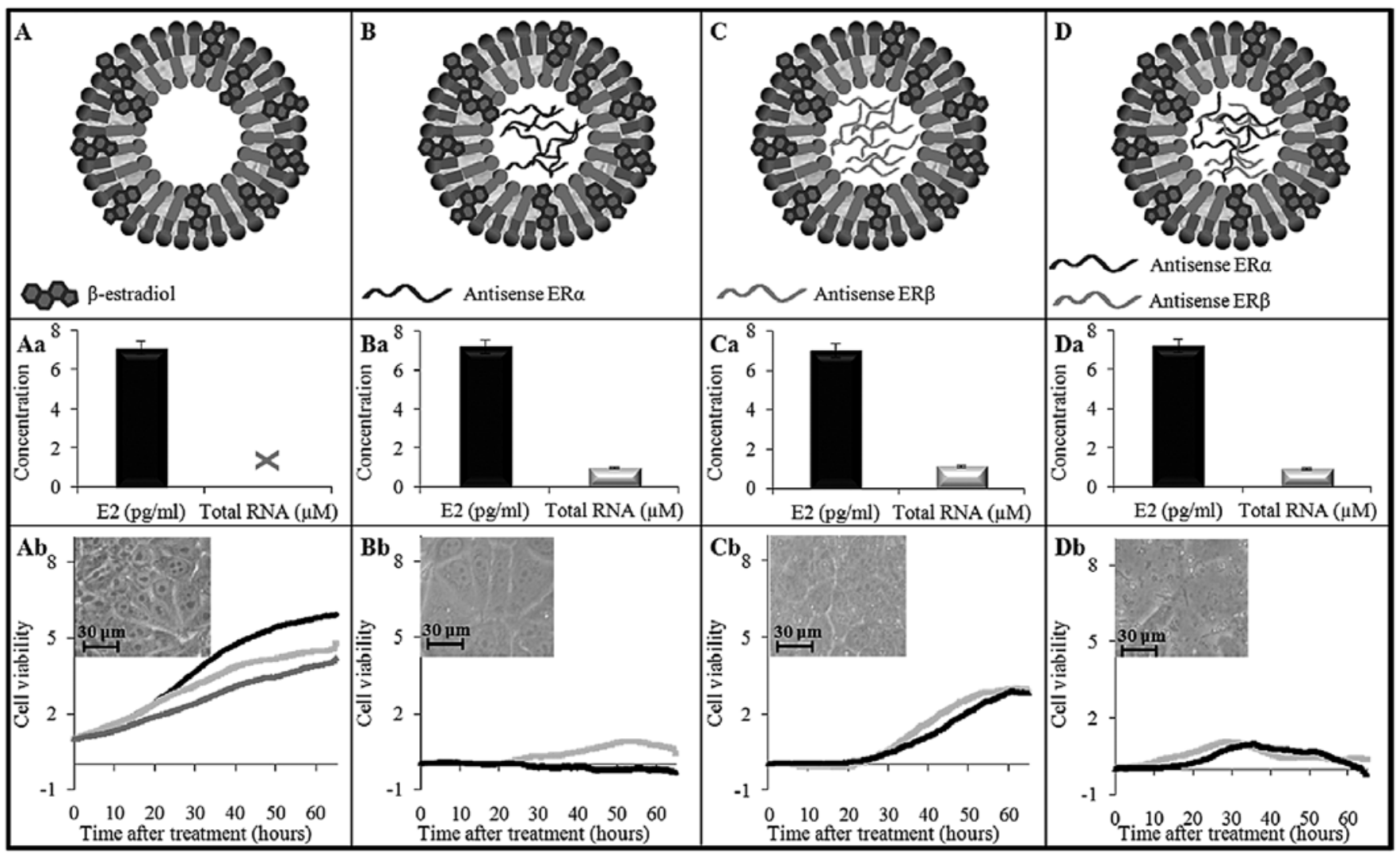

Figure 2. Tested liposomes: (A) liposome with no antisense oligonucleotides, (B) liposome containing antisense oligonucleotides ER $\alpha$, (C) liposome containing antisense oligonucleotides ER $\beta$ and (D) liposome containing both ER $\alpha$ and ER $\beta$ antisense oligonucleotides. (a) The content of $E_{2}$ and antisense oligonucleotides determined by immunochemistry and electrochemistry, respectively. (b) The influence of individual liposomes on cell viability, expressing the cell growth of MCF-7 on the electrode surface under the effect of liposome treatment, where dark grey stands for control (no liposomes applied), light grey stands for a $1 \mu \mathrm{M}$ concentration of liposomes applied and black for a $10 \mu \mathrm{M}$ concentration of liposomes applied into the medium to obtain a final volume of 6 ml. Insets: microscopic images of (Ab) MCF-7 control cells and (Bb-Db) MCF-7 cells after treatment with the highest amount of liposomes.

$7.125 \mathrm{pg} / \mathrm{ml}$ (Fig. 2Aa-Da). Subsequently, electrochemistry was employed for determination of the total RNA amount in the estradiol-based liposomes and it was revealed that unlike L1 (Fig. 2Aa), the other liposomes (L2, L3 and L4, respectively) contained concentrations from 0.91 to $1.12 \mu \mathrm{M}$ (average of $0.993 \mu \mathrm{M}$ ) of total-RNA (volume of solution, used for measurement: $100 \mu \mathrm{l}$ ). This finding approximately corre- sponds with the concentrations calculated prior to liposome synthesis $(1 \mu \mathrm{M})$. Thus, we confirmed that our lipidic thin-film hydration method of synthesis works properly.

Antiproliferative effect of $E_{2}$-based liposomes loaded with ASOs. The real-time cell-based assay (RTCA) was carried out to monitor the proliferation of MCF-7 epithelial breast cancer 


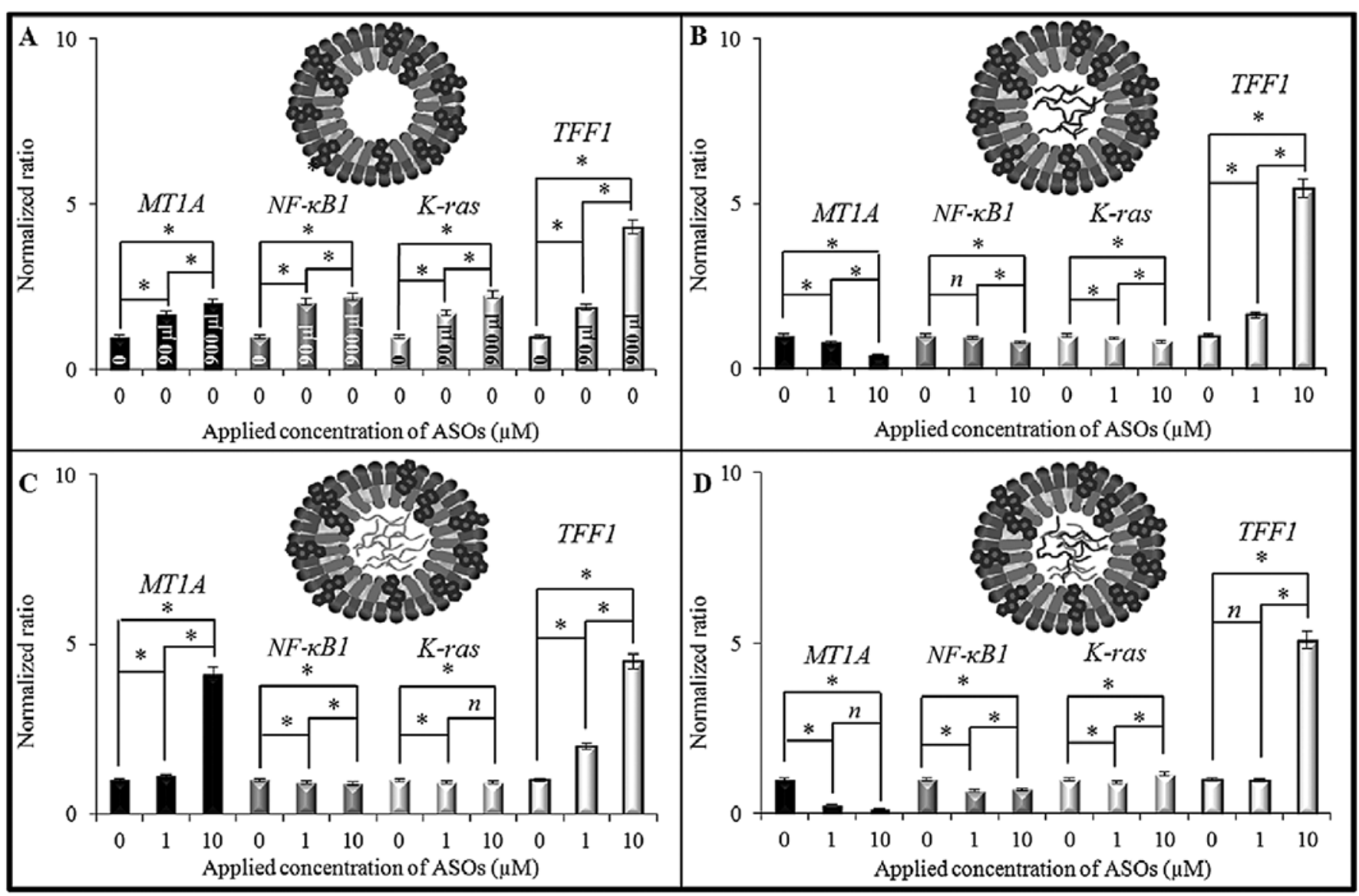

Figure 3. Effect of various 17ß-estradiol liposomes containing ER antisense sequences on MCF-7 cell culture. The expression levels of $M T 1 A, N F-\kappa B 1, K$-ras and TFF1 genes were observed. Schematic representations are connected to the gene expression and show the scheme of $\mathrm{E}_{2}$-based liposomes: (A) with no antisense oligonucleotide (control), (B) containing ER $\alpha$ ASO, (C) containing ER $\beta$ ASO and (D) containing both ER $\alpha$ and ER $\beta$ ASOs. Liposomes were applied at concentrations of 0,1 and/or $10 \mu \mathrm{M}$ into the medium. In the case of L1 (no ASOs) 0,90 and $900 \mu \mathrm{l}$ of the liposome solution was applied, corresponding to the amounts of $\mathrm{E}_{2}$-liposomes present in the case of 0,1 and $10 \mu \mathrm{M}$ ASOs in L2, L3 and L4. *Statistically significant differences between gene expression at $\mathrm{P}=0.05$ level; $\mathrm{n}$ indicates no statistical significance. ASOs, antisense oligonucleotides.

cells after application of the liposomes. The MCF-7 cells were derived from estrogen receptor-positive ductal carcinoma (23) and thus we chose this cell line for monitoring cell viability influenced by the estradiol-based liposomes. As shown in Fig. 2Ab, the application of increasing volumes of $\mathrm{L} 1(0,90$ or $900 \mu \mathrm{l}$ ) increased the proliferative effect (expressed as cell viability) of MCF-7 cells. This finding was expected due to the proliferative properties of MCF-7 cells in response to $E_{2}$ as previously described by Lacroix and Leclercq (23) and Resende et al (24).

To reflect the real antiproliferative effect of ASOs, we subtracted the cell viability of the controls (L1) from the test samples (Fig. 2Bb-Db). Antisense against ER $\alpha$ was shown to decrease the proliferative ability of MCF-7 cells, since their proliferation is controlled by ER $\alpha$-mediated gene regulation as described previously (25). While $\mathrm{E}_{2}$ stimulates proliferation via $E R \alpha$, the signaling via $E R \beta$ inhibits proliferation and promotes apoptosis (26). It was shown in transfection studies in breast and colon cancer cells that the lack of ER $\beta$ proteins leads to increased cell proliferation both in culture and in vivo xenografts $(27,28)$. Based on this information, ER $\beta$ was suggested to be a pro-apoptotic tumor suppressor (29) and thus alteration of protein translation subsequently elevated MCF-7 cell proliferation (Fig. 2Cb). Notably, the synergistic effect of both ASOs was shown to also have antiproliferative effects, but after a relatively long exposure time (Fig. 2Db). This phenomenon may be caused by a strong duplexing effect of antisense oligonucleotides complementary to mRNA encoding ER $\alpha$ translation and conversely only a weak complementary affinity to mRNA encoding ER $\beta$. Therefore, despite the treatment with ASOs, the translation pathway was still able to produce ER $\beta$ proteins at threshold concentrations.

Liposomes are preferentially internalized through caveolae-dependent endocytosis (21), where the main role is played by acidification of the endocytic vesicle permitting release of antisense oligonucleotides rather than liposome membrane fusion. Therefore, in the micrographs of MCF-7 cells after liposome application, it can be observed that the cell size was increased due to endosome formation (insets in Fig. 2Ab-Db).

Influence of $E_{2}$-based liposomes on MCF-7 cell selected gene expression. First, we decided to monitor the expression activity of the MTIA gene encoding metallothionein (MT) protein. MT is primarily responsible for metal sequestration and detoxification. It was previously shown that metallothio- 
nein expression is modulated also by $\mathrm{E}_{2}$ in in vivo studies using fish experimental models $(30,31)$, where a positive correlation between $M T 1 A$ expression and $\mathrm{E}_{2}$ levels was described in muscle tissue in contrast to liver and intestines. Our results revealed that the application of $\mathrm{E}_{2}$-based liposomes with no cargo elevated the MTIA expression by more than $60 \%(90 \mu 1$ of $\mathrm{L} 1$ added) or $100 \%$ (900 $\mu \mathrm{l}$ of $\mathrm{L} 1$ added), when compared with the control (Fig. 3A), determined by expression of the gene without application of liposomes standardized to $\beta$-actin (labeled as $0 \mu \mathrm{l}$ ). The increase in gene expression may be attributed to a defense mechanism in response to oxidative stress caused by the presence of $\mathrm{E}_{2}$ (32). Importantly, after the application of liposomes containing ASOs (1 and $10 \mu \mathrm{M})$ against ER $\alpha$ protein (L2), it was shown that MT1A expression was downregulated (by $>15$ and/or 55\%, respectively, Fig. 3B). This phenomenon points to a successful steric blockade of the $\mathrm{ER} \alpha$ translational start site resulting in protein depletion and therefore downregulation of transcription related to $\mathrm{E}_{2}$-ER binding with subsequent effect on the MT1A gene. After the application of ASOs (10 $\mu \mathrm{M})$ against ER $\beta$ (L3), a significant increase in expression of the metallothionein gene was observed (Fig. 3C). Proper translation of the ER $\beta$ protein seems to be important for the regulation of the MT1A gene. Although the role of $\operatorname{ER} \beta$ is still under investigation in breast cancer, it was previously shown that $\operatorname{ER} \beta$ acts as a tumor suppressor (33). Moreover, we offer evidence that ER $\beta$ downregulation directly influences the expression of the $M T 1 A$ gene in MCF-7 cells. After treatment with the liposomes carrying both ASOs (L4), we observed a similar effect on MT1A $(\sim 75$ and/or $85 \%$ downregulation after addition of 1 and $10 \mu \mathrm{M}$ ASOs, respectively) as in the case of treatment with ASOs against $\mathrm{ER} \alpha$ (Fig. 3D). Low threshold concentrations were required to trigger an antisense effect of ER $\alpha$ ASOs. On the other hand, ER $\beta$ functions were not significantly influenced when compared with ER $\alpha$ and thus the desired effect was observed.

Furthermore, the expression activity of the $N F-\kappa B l$ gene was determined, as the blocking of $N F-\kappa B l$ can cause tumor cells to stop proliferation, to die, or to become more sensitive to the action of chemotherapeutics (34). NF- $\kappa$ B1 transcription factor influences various molecules involved in oncogenesis such as matrix metalloproteinases (MMPs), their activators and/or inhibitors, cell adhesion molecules and angiogenic factors (35). In the present study, $N F-\kappa B l$ expression was upregulated in MFC-7 cells after treatment with L1 ( 100 and $120 \%$ after the application of 90 and $900 \mu 1$, respectively) (Fig. 3). This indicates the ability of $E_{2}$ to influence MCF-7 cells undesirably. When compared with the application of ASOs, the highest effect was observed after treatment with $\mathrm{ER} \alpha$, where downregulation of $\sim 5 \%$ was observed at $1 \mu \mathrm{M}$ ASOs and $\sim 20 \%$ at $10 \mu \mathrm{M}$ ASOs (Fig. 3B). The effect of both ASOs was also shown to trigger downregulation of $N F-\kappa B 1$ by $\sim 35 \%$ at $1 \mu \mathrm{M}$ ASOs or $30 \%$ at $10 \mu \mathrm{M}$ ASOs (Fig. 3D). The ASOs against ER $\beta$ were found to influence $N F-\kappa B 1$, because a downregulation $\sim 9 \%$ was observed in the case of $1 \mu \mathrm{M}$ ASOs and further $10 \%$ in the case of $10 \mu \mathrm{M}$ ASOs (Fig. 3C), when compared with the L1 liposome. Nevertheless, the best results were obtained using liposome L2 and L4. This phenomenon suggests that the presence of ASOs against $\mathrm{ER} \alpha$ is more crucial for the downregulation of expression of
$N F-\kappa B 1$ than ER $\beta$. Based on these results, it can be concluded that ASOs may offer the possibility to inhibit $N F-\kappa B l$ gene activity and thus increase the efficiency of chemotherapeutics applicable in breast cancer treatment.

Moreover, we determined $K$-ras gene expression, which was influenced in a similar way as $N F-\kappa B 1$. The expression of $K$-ras was elevated with increasings amounts of L1 applied ( $\sim 70$ and $125 \%$ at 1 and $10 \mu \mathrm{M}$ of ASOs, respectively) (Fig. 3A). The application of ASOs exhibited a downregulatory influence on $K$-ras expression (Fig. 3B-D). The greatest effect was determined at $10 \mu \mathrm{M}$ antisense against ER $\alpha$ (Fig. 3B). In the case of ASOs against ER $\beta$, no significant differences between 0 and $1 \mu \mathrm{M}$ application were observed at $\mathrm{P}<0.05$; and moreover, a $10 \mu \mathrm{M}$ concentration resulted in a downregulation of only $7.5 \%$ when compared to $0 \mu \mathrm{M}$ (Fig. 3C). The ER $\alpha$ ASO influence on $K$-ras gene expression may serve as a potential tool to inhibit K-ras activity, as K-ras and ER proteins are linked in K-ras 4B-mediated cell transformation by p53-independent modulation of MDM2 functions as identified by Kato et al (36). Because of the fact that ER can be considered as one of the effectors of the Ras/Raf signaling pathway involving in tumorigenesis (37), the inhibition of estrogen receptor activity subsequently triggers the downregulation of the expression of K-ras. However, the relationship of these two factors is still not satisfactorily elucidated.

TFF1 gene encoding $\mathrm{pS} 2$ protein was also determined as the only one that was not downregulated by our antisense strategy. When comparing control liposome L1 (Fig. 3A) with liposomes loaded with ASOs (Fig. 3B-D), it is obvious that $\mathrm{E}_{2}$, but not ASOs, plays a crucial role in $T F F 1$ expression due to the significant differences $(\mathrm{P}<0.05)$ between 0,1 and $10 \mu \mathrm{M}$ concentrations of ASOs observed for all liposomes including L1. The induction phenomenon of TFF1 expression was found to be primarily due to a response to estrogens and was mediated by the binding of the ER- $\mathrm{E}_{2}$ complex to a 13-bp near-palindromic ERE located 400 bases upstream of the TFF1 transcription start site $(38,39)$. Hence, the presence of $\mathrm{E}_{2}$, which forms a complex with transcription factors, directly influences also the $T F F 1$ transcription start site. As numerous studies have shown that TFF1 does not act as an oncogene in the mammary gland, but conversely, exerts a beneficial function during malignant processes in ER-positive breast tumors $(38,40-42)$, our results point to the potential positive effect caused by our antisense strategy.

Oxidative stress determination after $E_{2}$-based liposome application. Numerous signaling pathways, which are linked to tumorigenesis, can also regulate the metabolism of ROS through various mechanisms. As mentioned in a review by Gorrini et al, high ROS levels are generally harmful to cells, and the redox status of cancer cells is usually higher than that in healthy cells due to metabolic and signaling aberrations (43). For this reason, we assessed oxidative stress indicators, particularly glutathione, metallothionein and malondialdehyde to obtain a more detailed insight into the manner that $\mathrm{E}_{2}$-based liposomes act on MCF-7 cells at the molecular level.

It has been reported that elevated GSH levels are present in various types of tumors and thus neoplastic tissues are more resistant to chemotherapy (44). In malignant cells, an increased GSH level is associated with a proliferative response 


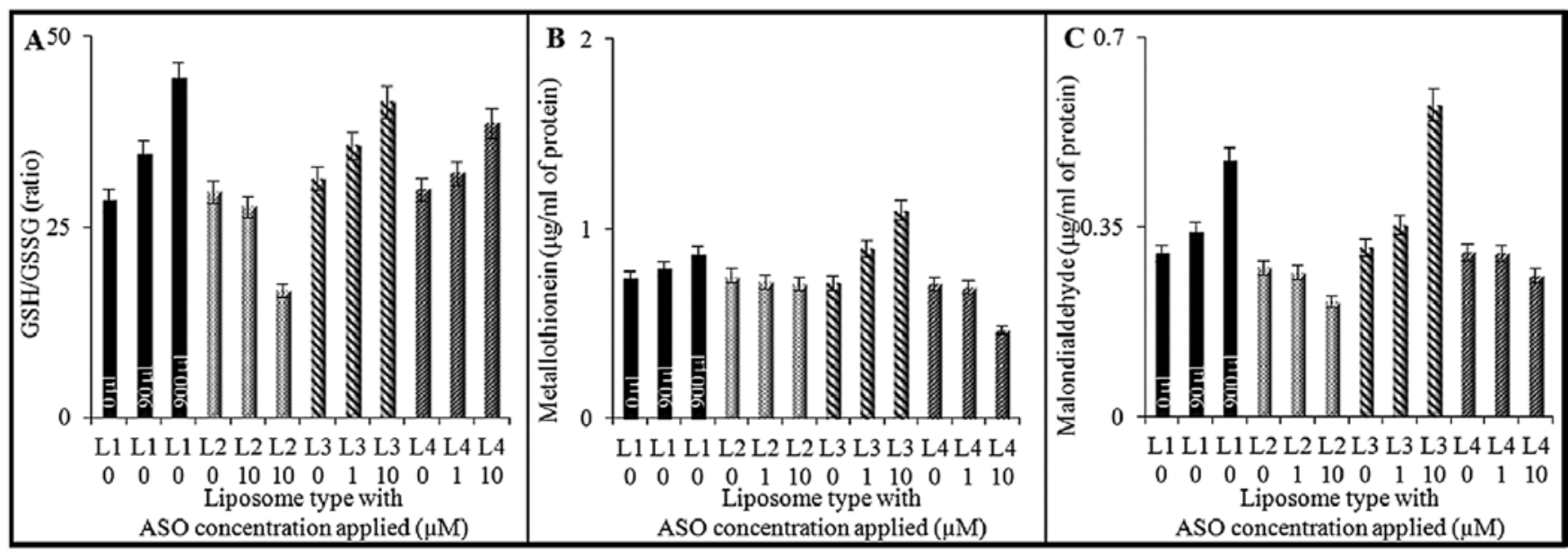

Figure 4. Expression of oxidative stress markers determined in the MCF-7 cell line after treatment with the different types of liposomes. (A) GSH/GSSG ratio, (B) metallothionein and (C) malondialdehyde. Liposomes are indicated as follows: L1, liposome containing E2 with no antisense sequence; L2, liposome containing $E_{2}$ with antisense sequence $E R \alpha ; L 3$, liposome containing $E_{2}$ with antisense sequence ER $\beta$ and L4, liposome containing $E_{2}$ and both ER $\alpha$ and $E R \beta$ antisense sequences. Liposomes were applied at concentrations of 0,1 and/or $10 \mu \mathrm{M}$ into the medium to obtain a final volume of $6 \mathrm{ml}$. In the case of L1 (no ASOs), 0,90 and/or $900 \mu 1$ of liposome solution was applied corresponding to the amount of liposomes present in the case of 0,1 and/or $10 \mu \mathrm{M}$ ASOs in L2, L3 and L4. ASOs, antisense oligonucleotides.

and is essential for cell cycle progression; yet, the molecular mechanism of how GSH modulates cell proliferation remains largely speculative. As shown in Fig. 4A, the addition of liposomes L1, L3 and L4 caused an elevation in GSH levels due to the presence of $\mathrm{E}_{2}$ in all cases and moreover ASOs against ER $\beta$ in the case of L3 and L4. These data also corroborate the RTCA results, where the presence of $\mathrm{E}_{2}$ and ASOs towards ER $\beta$ resulted in the increased proliferation of MCF-7 cells. On the other hand, the application of L2 (Fig. 4A) dramatically decreased the glutathione redox ratio (similar trend to the cell index of MCF-7). Hence, the application of $\mathrm{E}_{2}$-based liposomes carrying ASOs may be helpful to decrease the resistance to chemotherapy caused by high levels of GSH in tumor tissues.

Furthermore, metallothionein levels were assessed (Fig. 4B). Liposomes L2 and L4 were found to have a suppressive effect on protein formation. In the case of L2, an application of $0 \mu \mathrm{M}$ ASOs resulted in $0.75 \mu \mathrm{g}$ of metallothionein (standardized to $1 \mathrm{ml}$ of total protein); $1 \mu \mathrm{M}$ ASOs resulted in $0.72 \mu \mathrm{g}$ of metallothionein to $1 \mathrm{ml}$ of total protein and $10 \mu \mathrm{M}$ ASOs resulted in $0.7 \mu \mathrm{g}$ of metallothionein to $1 \mathrm{ml}$ of total protein (Fig. 4B). The application of L4 at a concentration of $0 \mu \mathrm{M}$ ASOs resulted in $0.71 \mu \mathrm{g}$ of metallothionein to $1 \mathrm{ml}$ of total protein; $1 \mu \mathrm{M}$ ASOs resulted in $0.69 \mu \mathrm{g}$ of metallothionein to $1 \mathrm{ml}$ of total protein and $10 \mu \mathrm{M}$ ASOs resulted in $0.46 \mu \mathrm{g}$ of metallothionein to $1 \mathrm{ml}$ of total protein. This corresponds to the results obtained from qRT-PCR. Surowiak et al reported that the elevated level of lowmolecular-weight metallothionein in estrogen receptor-positive breast tumors may be explained by endoplasmic reticulum damage or by its malfunction and can be found typically in breast cancer cases with less favorable prognosis (41). It was shown that the effective application of ASOs may serve as a potential tool to mitigate the damage of endoplasmic reticulum and thus decrease the levels of metallothionein. Moreover, metallothionein was shown to be one of the potential co-factors causing the chemoresistance of tumors to platinum-based cytostatics and to anthracyclines (45-48). Hence, the downregulation of MT expression via ASO targeting of the MTIA gene may enhance tumor cell susceptibility to various chemotherapeutic agents.

Malondialdehyde (MDA) is one of the final decomposition products of lipid peroxidation and it is also formed as a product of the cyclooxygenase reaction in prostaglandin metabolism (49). It clearly follows from the results obtained that our novel strategy for antisense therapy was efficient in the case of MDA, as ASOs against $\mathrm{ER} \alpha$ (10 $\mu \mathrm{M}$ application) showed a decrease in its level; $>0.06 \mu \mathrm{g}$ of MDA to $1 \mathrm{ml}$ of total protein when compared to the control (Fig. 4C). Similarly, a slightly reducing effect was also observed in the case of the combination of both ASOs. As MDA reacts with double-stranded DNA to form mutagenic adducts and lipid peroxidation appears to be a major source of endogenous DNA damage in humans significantly contributing to tumor development (50), the reduction in lipid peroxidation end products may be one of the very significant effects of antisense therapy suggested by us.

In conclusion, we suggest four types of liposomes based on $E_{2}$ placed in their lipid bilayer substituting commonly used cholesterol. As a cargo, antisense oligonucleotides towards estrogen receptor $\alpha$ and $\beta$ were applied, and it was revealed that the liposomes synthesized by us showed a beneficial response in regards to a decrease in proliferation of MCF-7 cells. Moreover, it was shown that besides $T T F 1$, the antisense strategy downregulated evaluated genes (MTIA, K-ras and $N F-\kappa B I)$ and also decreased the levels of oxidative stress indicators (MT, GSH/GSSG and MDA). We conclude that antisense ER $\alpha$ efficiently binds to ER $\alpha$ mRNA and thus the translation of nascent ER $\alpha$ protein is inhibited. Furthermore, the therapeutic strategy based on our ASOs entrapped in $\mathrm{E}_{2}$-based liposomes offers the possibility to enhance tumor susceptibility to chemotherapeutics via GSH oxidation and downregulation of MT expression through ASO targeting of the MT1A gene. Therefore, ASOs can be useful in cases where single treatment therapy does not show adequate results and chemosensitization of the tumor is required. 


\section{Acknowledgements}

This study was supported by the Internal Grant Agency of the University of Veterinary and Pharmaceutical Sciences Brno, Czech Republic (Project 4/2013/FVHE) and CEITEC CZ.1.05/1.1.00/02.0068.

\section{References}

1. Zamecnik PC and Stephenson ML: Inhibition of Rous sarcoma virus replication and cell transformation by a specific oligodeoxynucleotide. Proc Natl Acad Sci USA 75: 280-284, 1978.

2. Warzocha K: Antisense strategy in hematological malignancies. Cytokines Cell Mol Ther 5: 15-23, 1999.

3. Ruden M and Puri N: Novel anticancer therapeutics targeting telomerase. Cancer Treat Rev 39: 444-456, 2013.

4. Wu Y, Zhang Y, Wang M, et al: Downregulation of HER3 by a novel antisense oligonucleotide, EZN-3920, improves the antitumor activity of EGFR and HER2 tyrosine kinase inhibitors in animal models. Mol Cancer Ther 12: 427-437, 2013.

5. Panyam J and Labhasetwar V: Biodegradable nanoparticles for drug and gene delivery to cells and tissue. Adv Drug Deliv Rev 55: 329-347, 2003.

6. Jones SE: Metastatic breast cancer: the treatment challenge. Clin Breast Cancer 8: 224-233, 2008.

7. Xie QC, Hu YD, Wang LL, et al: The co-transfection of p16(INK4a) and p14(ARF) genes into human lung cancer cell line A549 and the effects on cell growth and chemosensitivity. Colloids Surf B Biointerfaces 46: 188-196, 2005.

8. Stein CA: Two problems in antisense biotechnology: in vitro delivery and the design of antisense experiments. Biochim Biophys Acta 1489: 45-52, 1999.

9. Balbino TA, Azzoni AR and de la Torre LG: Microfluidic devices for continuous production of $\mathrm{pDNA} /$ cationic liposome complexes for gene delivery and vaccine therapy. Colloid Surf B Biointerfaces 111: 203-210, 2013.

10. Skoblov Mlu: Prospects of antisense therapy technologies. Mol Biol 43: 984-998, 2009 (In Russian).

11. Zhong J, Yao X, Li DL, et al: Large scale preparation of midkine antisense oligonucleotides nanoliposomes by a cross-flow injection technique combined with ultrafiltration and high-pressure extrusion procedures. Int J Pharm 441: 712-720, 2013.

12. Ye S, Yang W, Wang Y, et al: Cationic liposome-mediated nitric oxide synthase gene therapy enhances the antitumor effects of cisplatin in lung cancer. Int J Mol Med 31: 33-42, 2013.

13. Kim TI and Kim SW: Bioreducible polymers for gene delivery. React Funct Polym 71: 344-349, 2011.

14. Xu M, Kumar D, Srinivas S, et al: Parenteral gene therapy with p53 inhibits human breast tumors in vivo through a bystander mechanism without evidence of toxicity. Hum Gene Ther 8: 177-185, 1997.

15. Nakase M, Inui M, Okumura K, Kamei T, Nakamura $S$ and Tagawa T: p53 gene therapy of human osteosarcoma using a transferrin-modified cationic liposome. Mol Cancer Ther 4: 625-631, 2005.

16. Krejcova L, Hynek D, Kopel P, et al: Development of a magnetic electrochemical bar code array for point mutation detection in the H5N1 neuraminidase gene. Viruses 5: 1719-1739, 2013.

17. Kensova R, Kremplova M, Smerkova K, et al: Interactions of platinum-based cytostatics with metallothionein revealed by electrochemistry. Int J Electrochem Sci 8: 4472-4484, 2013.

18. Krystofova O, Sochor J, Zitka O, et al: Effect of magnetic nanoparticles on tobacco BY-2 cell suspension culture. Int J Environ Res Public Health 10: 47-71, 2012.

19. Misra SK, Naz S, Kondaiah P and Bhattacharya S: A cationic cholesterol based nanocarrier for the delivery of p53-EGFP-C3 plasmid to cancer cells. Biomaterials 35: 1334-1346, 2014.

20. Taylor AH, Pringle JH, Bell SC and Al-Azzawi F: Specific inhibition of estrogen receptor alpha function by antisense oligodeoxyribonucleotides. Antisense Nucleic Acid Drug Dev 11: 219-231, 2001.

21. Ruyra A, Cano-Sarabia M, Mackenzie SA, Maspoch D and Roher N: A novel liposome-based nanocarrier loaded with an LPS-dsRNA cocktail for fish innate immune system stimulation. PLoS One 8: e76338, 2013.
22. Dinu-Pirvu C, Ferdes M, Butu A, Ortan A and Ghica MV: Physicochemical investigation of low soluble biocompounds entrapped in lipid carriers. Farmacia 61: 182-192, 2013.

23. Lacroix M and Leclercq G: Relevance of breast cancer cell lines as models for breast tumours: an update. Breast Cancer Res Treat 83: 249-289, 2004.

24. Resende FA, de Oliveira AP, de Camargo MS, Vilegas W and Varanda EA: Evaluation of estrogenic potential of flavonoids using a recombinant yeast strain and MCF7/BUS cell proliferation assay. PLoS One 8: e74881, 2013.

25. Hu ZZ, Kagan BL, Ariazi EA, et al: Proteomic analysis of pathways involved in estrogen-induced growth and apoptosis of breast cancer cells. PLoS One 6: e20410, 2011.

26. Yakimchuk K, Jondal M and Okret S: Estrogen receptor $\alpha$ and $\beta$ in the normal immune system and in lymphoid malignancies. Mol Cell Endocrinol 375: 121-129, 2013.

27. Tu ZZ, Ma Y, Tian J, et al: Estrogen receptor $\beta$ potentiates the antiproliferative effect of raloxifene and affects the cell migration and invasion in HCT-116 colon cancer cells. J Cancer Res Clin Oncol 138: 1091-1103, 2012.

28. Li H, Tu Z, An L, Qian Z, Achilefu S and Gu Y: Inhibitory effects of ER $\beta$ on proliferation, invasion, and tumor formation of MCF-7 breast cancer cells - prognostication for the use of ER $\beta$-selective therapy. Pharm Biol 50: 839-849, 2012.

29. Hartman J, Lindberg K, Morani A, Inzunza J, Strom A and Gustafsson JA: Estrogen receptor beta inhibits angiogenesis and growth of T47D breast cancer xenografts. Cancer Res 66: 11207-11213, 2006.

30. Costa DD, Neto FF, Costa MD, et al: Vitellogenesis and other physiological responses induced by 17 -beta-estradiol in males of freshwater fish Rhamdia quelen. Comp Biochem Physiol C Toxicol Pharmacol 151: 248-257, 2010.

31. Woo S, Won H, Lee A and Yum S: Oxidative stress and gene expression in diverse tissues of Oryzias javanicus exposed to 17 $\beta$-estradiol. Mol Cell Toxicol 8: 263-269, 2012.

32. Bhat HK, Calaf G, Hei TK, Loya T and Vadgama JV: Critical role of oxidative stress in estrogen-induced carcinogenesis. Proc Natl Acad Sci USA 100: 3913-3918, 2003.

33. Li W, Jia M, Qin X, Hu J, Zhang X and Zhou G: Harmful effect of ER $\beta$ on BCRP-mediated drug resistance and cell proliferation in ER $\alpha / \mathrm{PR}$-negative breast cancer. FEBS J 280: 6128-6140, 2013

34. Garg A and Aggarwal BB: Nuclear transcription factor-kappaB as a target for cancer drug development. Leukemia 16: 1053-1068, 2002.

35. Chen F, Castranova V, Shi X and Demers LM: New insights into the role of nuclear factor-kappaB, a ubiquitous transcription factor in the initiation of diseases. Clin Chem 45: 7-17, 1999.

36. Kato K, Horiuchi S, Takahashi A, et al: Contribution of estrogen receptor alpha to oncogenic K-Ras-mediated NIH3T3 cell transformation and its implication for escape from senescence by modulating the p53 pathway. J Biol Chem 277: 11217-11224, 2002.

37. Tu Z, Gui L, Wang J, Li X, Sun P and Wei L: Tumorigenesis of K-ras mutation in human endometrial carcinoma via upregulation of estrogen receptor. Gynecol Oncol 101: 274-279, 2006.

38. Buache E, Etique N, Alpy F, et al: Deficiency in trefoil factor 1 (TFF1) increases tumorigenicity of human breast cancer cells and mammary tumor development in TFF1-knockout mice. Oncogene 30: 3261-3273, 2011.

39. May FE and Westley BR: Trefoil proteins: their role in normal and malignant cells. J Pathol 183: 4-7, 1997.

40. Corte MD, Tamargo F, Alvarez A, et al: Cytosolic levels of $\mathrm{TFF} 1 / \mathrm{pS} 2$ in breast cancer: their relationship with clinical-pathological parameters and their prognostic significance. Breast Cancer Res Treat 96: 63-72, 2006.

41. Surowiak P, Matkowski R, Materna V, et al: Elevated metallothionein (MT) expression in invasive ductal breast cancers predicts tamoxifen resistance. Histol Histopathol 20: 1037-1044, 2005.

42. Markicevic M, Petrovic A, Kanjer K, Neskovic-Konstantinovic Z and Nikolic-Vukosavujevic D: Estrogen-regulated cut-off values of $\mathrm{pS} 2$ and cathepsin D expression in breast carcinomas. Adv Exp Med Biol 617: 341-348, 2008.

43. Gorrini C, Harris IS and Mak TW: Modulation of oxidative stress as an anticancer strategy. Nat Rev Drug Discov 12: 931-947, 2013. 
44. Traverso N, Ricciarelli R, Nitti M, et al: Role of glutathione in cancer progression and chemoresistance. Oxid Med Cell Longev 2013: 972913, 2013.

45. Hishikawa Y, Abe S, Kinugasa S, et al: Overexpression of metallothionein correlates with chemoresistance to cisplatin and prognosis in esophageal cancer. Oncology 54: 342-347, 1997.

46. Endo T, Yoshikawa M, Ebara M, et al: Immunohistochemical metallothionein expression in hepatocellular carcinoma: relation to tumor progression and chemoresistance to platinum agents. J Gastroenterol 39: 1196-1201, 2004.
47. Yap X, Tan HY, Huang J, et al: Over-expression of metallothionein predicts chemoresistance in breast cancer. J Pathol 217: 563-570, 2009.

48. Kizek R, Adam V, Hrabeta J, et al: Anthracyclines and ellipticines as DNA-damaging anticancer drugs: recent advances. Pharmacol Ther 133: 26-39, 2012.

49. Klein S, Dell'Arciprete ML, Wegmann M, et al: Oxidized silicon nanoparticles for radiosensitization of cancer and tissue cells. Biochem Biophys Res Commun 434: 217-222, 2013.

50. Marnett LJ: Oxy radicals, lipid peroxidation and DNA damage. Toxicology 181-182: 219-222, 2002. 